\title{
Impacts of different media on constructed wetlands for rural household sewage treatment
}

\author{
Shibao Lu ${ }^{a}$, Xiaoling Zhang ${ }^{b}$, Jianhua Wang ${ }^{c,}{ }^{*}$, Liang Pei ${ }^{\mathrm{d}}$ \\ a School of Urban-rural Planning and Management, Zhejiang University of Finance and Economics, Hang Zhou 310018, China \\ ${ }^{\mathrm{b}}$ Department of Public Policy, City University of Hong Kong Shenzhen Research Institute, Shenzhen, China \\ c State Key Laboratory of Simulation and Regulation of Water Cycle in River Basin China Institute of Water Resources and Hydropower Research, China \\ ${ }^{\mathrm{d}}$ Key Laboratory of Water Cycle and Related Land Surface Processes, Institute of Geographic Sciences and Natural Resources Research, Chinese Academy of \\ Sciences, Beijing 100101, China
}

\section{A R T I C L E I N F O}

\section{Article history:}

Received 6 October 2015

Received in revised form

29 March 2016

Accepted 29 March 2016

Available online 27 April 2016

\section{Keywords:}

Rural domestic sewage

Constructed wetland

Dissolved oxygen

Media filler

Aquatic plants

\begin{abstract}
A B S T R A C T
Constructed wetland systems have been used for treating a variety of household and industrial wastewater; they are a wastewater treatment technology that has high economic efficiency and environmental effectiveness, especially for sewage treatment in rural areas. Medium filler plays an important role in wetland sewage treatment processes. By carrying out a problem analysis of the ineffective operation and treatment of traditional wetlands, this paper designs different constructed wetland fillers to treat rural household sewage. Using the same plants, this paper chooses four different fillers, namely maifanite, steel slag, bamboo charcoal and limestone as substrates to build constructed wetland systems, and studies rural household sewage treatment in order to examine their effects on the degradation of pollutants. The results show the removal efficiencies obtain good effect. The theoretical maximum adsorption capacities of all these media are ordered as: maifanite $>$ steel slag $>$ bamboo charcoal > limestone. The effluent water quality meets the first class A standard of the "Discharge standard of pollutants for municipal wastewater treatment plant" (GB18918-2002). The selection of medium has an important significance for the operating results of constructed wetland sewage treatment systems.
\end{abstract}

ㄷ) 2016 Elsevier Ltd. All rights reserved.

\section{Introduction}

For a long time, due to the shortage of funding for water pollution treatment and a weak awareness of water resources and environmental protection in rural China, household sewage has been directly discharged in rural areas without treatment, becoming the main reason for the decline in water quality of river and lake waterbodies, groundwater and water resources (Yang et al., 2015; Zhang et al., 2015). Therefore, it has become of urgent practical significance to study rural household sewage treatment techniques, explore suitable treatment models and promote the construction of a new socialist countryside.

Abbreviation: BOD, Biochemical Oxygen Demand; HRT, Hydraulic retention time; COD, Chemical Oxygen Demand; TP, Total phosphorus; TN, Total nitrogen; SS, Suspended solids.

* Corresponding author.

E-mail address: wjh@iwhr.com (J. Wang).
Constructed wetland sewage treatment systems are derived from the simulation of natural wetlands; they use the triple synergistic effects of natural ecosystems in physical, chemical and biological states to achieve sewage purification (Zhi and Ji, 2012; Grossmann, 2012). Depending on the length-to-width ratio and ground slope, particles fillers of a certain size (such as gravel, soil, peat, etc.) and aquatic plants, are used together to constitute the constructed wetland treatment system (Saumya et al., 2015; Lam et al., 2015). The aquatic plants generally used are beautiful and have good processing qualities (Boonsaner and Hawker, 2015; Mackul'ak et al., 2015), a high survival rate, strong water resistance, long growing seasons and high economic value (such as reeds, caltrops, iris, etc.). Together with animals and microorganisms that live in the water and filler, they form a unique flora and fauna environment. When the sewage flows through the patch surface and the gaps between patch fillers, an efficient purification can be achieved through filtration, adsorption, sedimentation, ion exchange, absorption by plants, microbial decomposition, etc. 
The study of constructed wetlands has its origin in the study of wetlands generally (Moreno et al., 2007; Gao et al., 2007). Constructed wetland is a type of sewage treatment process that began to develop in the 1970s (Hattermann et al., 2006; Vymazal et al., 2007). The constructed wetland treatment system artificially batches sewage with land that is usually in a submerged state and has aquatic plants growing (such as reeds, cattails, etc.), the sewage along a certain direction of flow is purified under the synergistic effects of water-resistant plants, soil and microorganisms (Benmoussa et al., 1997; Tachikawa and Yamanaka, 2014; Oshima et al., 2015). Due to the addition of human technology to their guidance, design and operation management, constructed wetlands have wider range of applications, more processing power and with improved treatment efficiency. In recent years, along with economic development and the increasing depletion of water resources, constructed wetlands have attracted the attention of most of countries around the world due to their high efficiency, low cost and excellent performance.

Constructed wetland systems have been used for treating numerous forms of wastewaters, mainly including industrial, rural household, urban household and nonpoint-source pollution, especially urban household sewage and nonpoint-source pollution (Matamoros and Salvadó, 2012; Galanopoulos et al., 2013; Shao et al., 2013). At present, constructed wetlands have been developed into a sewage treatment technology that has high economic efficiency and environmental effectiveness that is particularly suited to sewage treatment in rural areas.

The key elements of the applications of constructed wetlands in sewage treatment are plants and media (Dordio et al., 2007; Dordio and Carvalho, 2013; Wu and Zhang, 2015). Medium means filler can be used to intercept significant pollutants in sewage through sedimentation, filtration and adsorption. It is also the substance wherein the other active elements (plants and microorganisms) of constructed wetlands survive. Therefore, the selection of filler plays a key role in constructed wetlands to provide effective water purification. At present, typical constructed wetland fillers are zeolite, vermiculite, gravel, limestone, coal ash, slag, grit and soil, clay minerals and some industrial byproducts. Medium is the carrier in constructed wetland; its own physical and chemical properties may directly affect the sewage treatment efficiency of the whole system. In addition, when the inside of the patch is filled with a porous medium that has a large specific surface area, this can improve the hydraulic and mechanical properties of the wetland and provide microorganisms with a greater surface area for adhesion, enhancing the pollutant removal capacity of the system. Therefore, the selection of medium has great significance for the operational efficiency of the constructed wetland sewage treatment system.

The filler medium plays an important role in wetland processes for sewage treatment. At present, the wetlands treatment process makes wide use of grit sands, soil, gravels and other substrate fillers. The investment is more efficient (Verlicchi and Zambello, 2014 and Zhang et al., 2009), but the nitrogen and phosphorus removal efficiencies of these fillers are not ideal; therefore, experts have constantly developed new wetland fillers and carried out different levels of tests. Smol et al. (2015) use gravel patch and gravel-soil patch as constructed wetland fillers to test household sewage treatment. The results show the phosphorus removal efficiency of gravel-soil patch to be very good but that the ammonia nitrogen removal efficiency is much less so. An et al. (2014) show that natural zeolite can effectively absorb ammonia nitrogen in tap water, thus effectively reducing its ammonia nitrogen concentration. Hussain and Aziz (2011) have studied the capacity of three constructed wetlands namely zeolite, zeolite-limestone and limestone. The results show that the ammonia removal efficiencies of zeolite and zeolite-limestone wetland systems are very good. At the same time, Cui et al. (2013) have compared the removal efficiencies of different wetland fillers, concluding that the ammonia nitrogen removal efficiency of zeolite is significantly higher than that of gravel, but with a phosphorus removal efficiency of only $20 \%$. Vohla et al. (2011) use fly ash as a substrate filler in a wetland system to carry out an experimental study on household sewage, and compare their findings with the operating situations of gravel filler wetland systems. The results show that the removal efficiencies of a fly ash wetland system on nitrogen, phosphorus and organic substances in household sewage are good, of which ammonia nitrogen removal is clearly much higher than that with the gravel filler wetland system. Cui and Ouyang (2015) use coal ash and artificial soil as the filler in a subsurface-flow wetland treatment system to treat the effluent of a septic tank to demonstrate experimentally that the effluent concentration of TP meets the discharge standards. Zhang et al. (2015) also successfully use zeolite to remove ammonia nitrogen in urban sewage.

By carrying out a problem analysis of the ineffective operation and treatment of traditional wetlands, this experimental study designs different constructed wetland fillers for rural household sewage treatment. Using the same plants, four different fillers of maifanite, steel slag, bamboo charcoal and limestone are tested as substrates in building constructed wetland systems, and rural household sewage treatment is studied in order to examine its efficiency on the degradation of pollutants.

\section{Experimental section}

\subsection{Experimental apparatus and methods}

The experiment uses stepcase constructed wetlands, which is a type that belongs to composite vertical upward-flow subsurfaceflow constructed wetlands. The structure is shown in Fig. 1 (see Lu et al., 2015. The trapezoidal concrete pond has a height of $160 \mathrm{~cm}$, a longer base length of $3 \mathrm{~cm}$ and shorter base length of $1.7 \mathrm{~cm}$; the total thickness of the substrate layer is $80 \mathrm{~cm}$, and there is a $40 \mathrm{~cm}$ thick soil layer on the top of the substrate layer. The influent reservoir baffle has a height of $140 \mathrm{~cm}$ and the influent sediment pond baffle has a height of $120 \mathrm{~cm}$. A large gravels layer stands beneath the influent sediment pond baffle, and there is a portion of connectivity between the influent channel and the large gravel layer. The effluent sediment pond baffle has a height of $100 \mathrm{~cm}$ and the effluent reservoir baffle has a height of $80 \mathrm{~cm}$.

The working principle of this apparatus is that the rural household sewage enters into the concrete pond through the influent pipe, after which it first enters into the sewage sediment pond for sedimentation, and then overflows from the influent reservoir baffle to penetrate into the substrate layer through the influent channel. This means that, when it penetrates into the substrate layer from the beneath of the influent sediment pond, it goes through the substrate filler layer and soil layer from bottom to top and, after the filtration process, overflows through the effluent sediment pond baffle into the effluent sediment pond, before overflowing again into the effluent reservoir when the effluent sediment pond is full. There are aquatic plants on the wetland soil layer. Perforated tubes and sampling tubes are vertically set up along the middle of the patch in order to take water samples and measure dissolved oxygen, temperature, $\mathrm{pH}$ and other parameter values within the wetlands. The apparatus operated from April 2012 to August 2012, running in good condition.

The hydraulic retention time (HRT) in this experiment was set to a 7 day period. The COD, turbidity, NH3-N, TN and TP of influent and effluent water was measured 7 consecutive times, and their removal efficiencies finally calculated. 


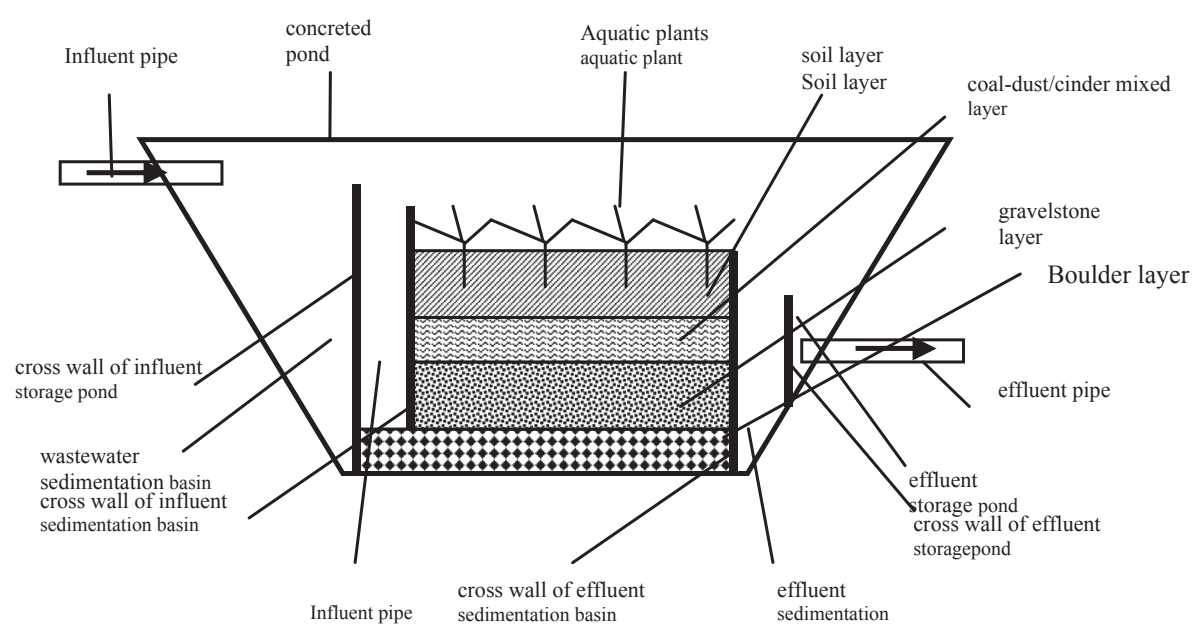

Fig. 1. Schematic diagram of staircase constructed wetland.

\subsection{Water quality analysis methods}

The water quality of the influent water, effluent water and water samples respectively from various sampling points was analyzed each week, using measuring methods in accordance with the 2002 "Water and Wastewater Monitoring and Analysis Methods" released by the Ministry of Environmental Protection of the People's Republic of China (MEP), formerly State Environmental Protection Administration (SEPA). The COD was measured using the potassium dichromate method, i.e., the alkaline potassium persulfate digestion-UV spectrophotometric method; $\mathrm{NH}_{3}-\mathrm{N}$ was measured using Nessler's reagent colorimetric method; NO2-N using the spectrophotometric method and the phenol disulfonic acid spectrophotometric method; TP using the ammonium molybdate spectrophotometric method; Suspended solids (SS) the gravimetric method; $\mathrm{pH}$ the electrode method; and the dissolved oxygen (DO) immediately measured using a YSL 5000 DO meter after on-site sampling. The number of nitrifying bacteria in the constructed wetland substrates was measured using the FISH method (Samsó and García, 2013); and the number of denitrifying bacteria was measured using MPN method.

The experiment used rural household sewage as raw water; the raw water quality and analysis methods are shown in Table 1.

\section{Results and analysis}

\subsection{Effects of different substrates on COD concentration}

Studies have shown that different substrates play a certain role in COD removal efficiency (Wei Yang et al., 2015), because the substrate itself can not only absorb some inorganic pollutants, but also substrate that has a larger surface area can create good living conditions for the reproduction and role of microorganisms, so that they can more efficiently carry out the effective adsorption, absorption and degradation of water pollutants in the sewage.

As can be seen in Fig. 2, among the four substrates, the COD removal efficiencies of maifanite and steel slag are best, and the removal efficiency of the maifanite system is better than that of the steel slag system; with the increase in HRT, the COD removal efficiency gradually increases, and it eventually becomes smoother. The limestone system has lower removal efficiency while, with the increase of HRT, the COD removal efficiency changes a little. When HRT is after four days, the removal efficiency remained unchanged; when HRT is at 5 days, the COD removal efficiencies of all four substrates become stable. Take HRT $=7$ days, the COD removal efficiencies of steel slag, limestone, maifanite and bamboo charcoal are $79.7 \%, 73.6 \%, 81.3 \%$ and $67.6 \%$, respectively; the average COD concentrations in the final effluent are $51.2 \mathrm{mg} / \mathrm{L}, 61.3 \mathrm{mg} / \mathrm{L}$, $53.2 \mathrm{mg} / \mathrm{L}$ and $93.4 \mathrm{mg} / \mathrm{L}$, respectively. Among these four substrates, maifanite and steel slag have larger specific surface areas and maifanite is relatively softer; consequently, the efficiency of the interception, adsorption and absorption of pollutants is better, and provide a more advantageous growing environment of microorganisms (Bajaj and Singh, 2015).

Therefore, the COD removal efficiencies of maifanite and steel slag are better than those of limestone and bamboo charcoal.

\subsection{Effects of different substrates on turbidity concentration}

As is evident in Fig. 3, the turbidity removal efficiency trends of all four substrates are very similar. With the increase of HRT, turbidity removal efficiency increases. When HRT is at 4 days, the turbidity removal efficiencies of steel slag, limestone, maifanite and bamboo charcoal systems are $88.7 \%, 70.7 \%, 89.7 \%$ and $67.6 \%$ respectively. As HRT continues to increase, the increase in turbidity removal efficiency is less obvious. The turbidity removal efficiency of the substrate depends mainly on the adsorption on the substrate specific surface area and the large number of adherent microorganisms that form a large biofilm, playing the role of filtration. Therefore, the turbidity removal efficiency is higher for filler with a small particle size and irregular shape (Lu et al., 2016 and Chou et al., 2009). Steel slag, maifanite and bamboo charcoal have a small particle size and irregular shape, while maifanite and bamboo charcoal materials are softer and easier to adsorb pollutants; therefore, their turbidity removal efficiencies are better. When HRT reaches 5 days, the average effluent turbidity concentrations for all four substrates reach 16.4 NTU, 26.3 NTU, 11.5 NTU and 13.3 NTU respectively.

Using the stepcase constructed wetlands of these four substrates for rural household sewage treatment, the effluent turbidity indexes met the first class of A standard of the "Discharge standard of pollutants for municipal wastewater treatment plant" (GB189182002).

\subsection{Effects of different substrates on TP concentration}

The TP removal of constructed wetlands depends mainly on the constructed wetland filler layer's substrate, the aquatic plants and 
Table 1

Methods, items and raw water quality of the test.

\begin{tabular}{lcl}
\hline Item & Value & Analysis method \\
\hline $\mathrm{COD}_{\mathrm{Cr}}\left(\mathrm{mg} \cdot \mathrm{L}^{-1}\right)$ & $186-341$ & Potassium dichromate method \\
$\mathrm{BOD}_{5}\left(\mathrm{mg} \cdot \mathrm{L}^{-1}\right)$ & $82-166$ & Dilution-inoculation method \\
$\mathrm{NH}_{3}-\mathrm{N}\left(\mathrm{mg} \cdot \mathrm{L}^{-1}\right)$ & $38-97$ & Nessler's reagent colorimetric method \\
$\mathrm{TN}\left(\mathrm{mg} \cdot \mathrm{L}^{-1}\right)$ & $59-134$ & Ultraviolet spectrophotometric method \\
$\mathrm{TP}\left(\mathrm{mg} \cdot \mathrm{L}^{-1}\right)$ & $3.4-13.9$ & Ammonium molybdate spectrophotometric method \\
Temperature $\left({ }^{\circ} \mathrm{C}\right)$ & $16-35$ & Thermometer \\
$\mathrm{pH}$ & $6-9$ & Glass electrode method \\
$\mathrm{DO}$ & $0.049-0.031$ & YSL 5000 DO meter \\
\hline
\end{tabular}

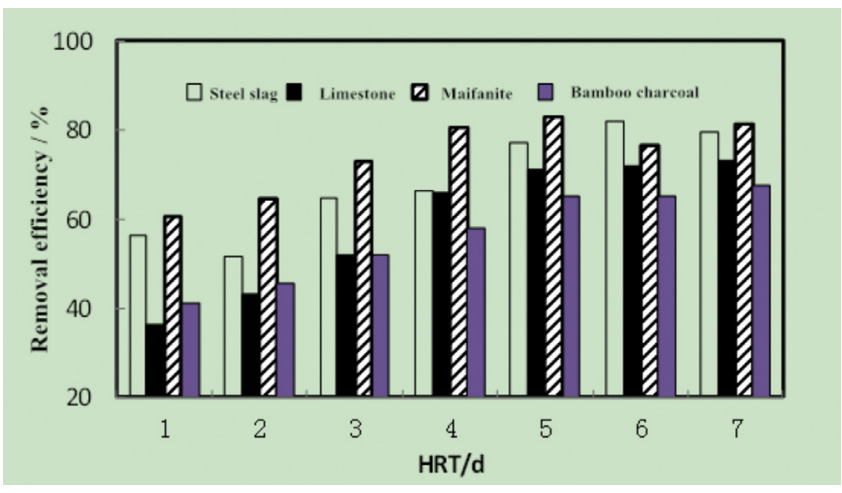

Fig. 2. Variations of COD removal efficiency with HRT.

microorganisms, as well as the combined effects of the three. The constructed wetlands filler plays the most important role in TP removal, with the combined effect of aquatic plants and microorganisms being second only after the filler substrate. Among the four substrate systems, the transformation of phosphorus composites by microorganisms is a restrictive factor in the TP purification process; the stability of wetland substrates strengthens TP adsorption and absorption by microorganisms (Pang et al., 2013). The phosphorus removal efficiency of the steel slag system is stronger than that of other substrates. Also, with the increase of HRT, the phosphorus removal efficiency of the steel slag system remains constant at a high level, while the removal efficiencies of the limestone, maifanite and bamboo charcoal systems are relatively poor.

As can be seen in Fig. 4, when the HRT reaches 5 days, the TP removal efficiency of limestone system begins to decline. This may be because the specific surface area of limestone is small, so when substrate adsorption reaches saturation point, TP removal relies solely on adsorption and degradation. When HRT is over 6 days, the TP removal efficiency of bamboo charcoal system also declines; while the removal capabilities of steel slag and maifanite systems become gradually smooth and saturated. This shows that the TP removal in sewage to be more reasonable when HRT is at 6 days or so. Therefore, when HRT $=6$ days, the TP removal efficiencies of steel slag, limestone, maifanite and bamboo charcoal systems are $83.5 \%, 55.2 \%, 78.6 \%$ and $69.2 \%$, respectively. The average TP concentration indices in the final effluents are $0.21 \mathrm{mg} / \mathrm{L}, 0.59 \mathrm{mg} / \mathrm{L}$, $0.38 \mathrm{mg} / \mathrm{L}$ and $0.40 \mathrm{mg} / \mathrm{L}$ respectively.

\subsection{Effects of different substrates on TN concentration}

As can be seen in Fig. 5, with the increase of HRT, the TN removal efficiencies of all four substrates continues to grow; when HRT is greater than 5 days, the TN removals of the substrates stabilizes. Except for the absorption by fillers and plants, TN removal is also affected factors such as the volatilization of ammonia, adsorption by substrates and the reaction of filtration, nitrification and denitrification, etc.; of which TN removal relies mainly on nitrification and denitrification by microorganisms (Mayo et al., 2014; Feng et al., 2015). The more developed the root system of the aquatic plants, and the stronger the stability and larger the specific surface area of the substrates, the more it provides a good breeding environment for nitrifying bacteria. Namely, a good aerobic microenvironment is more conducive to full nitrification of TN; therefore, the treatment efficiencies of steel slag and maifanite are better than those of limestone and bamboo charcoal. When HRT is at 6 days, the TN removal efficiencies of steel slag, limestone, maifanite and bamboo charcoal systems are $74.4 \%, 50.1 \%, 79.2 \%$, and $69.2 \%$ respectively. The average TN concentration indices in the final effluents are $6.92 \mathrm{mg} / \mathrm{L}, 13.71 \mathrm{mg} / \mathrm{L}, 8.87 \mathrm{mg} / \mathrm{L}$ and $11.4 \mathrm{mg} / \mathrm{L}$ respectively.

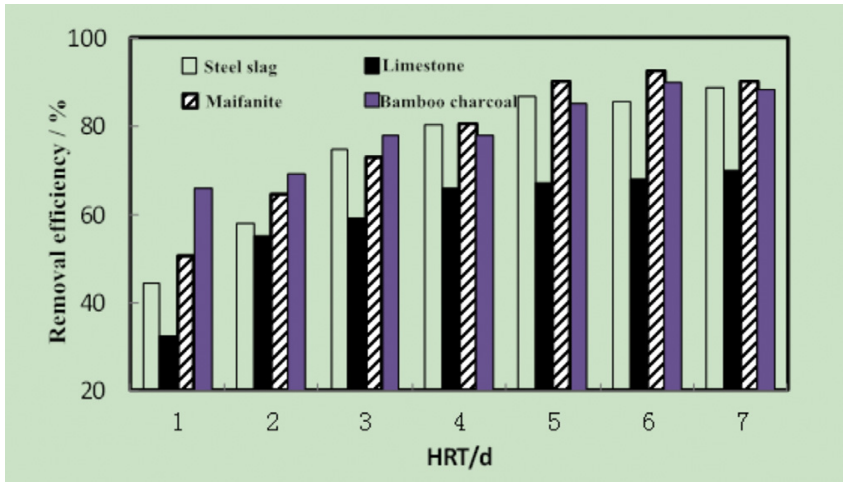

Fig. 3. Variations of turbidity removal efficiency with HRT.

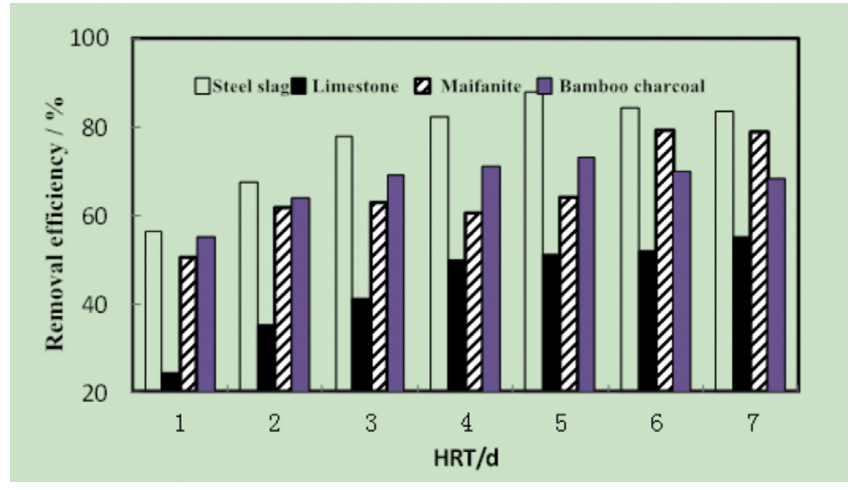

Fig. 4. Variations of TP removal efficiency with HRT. 


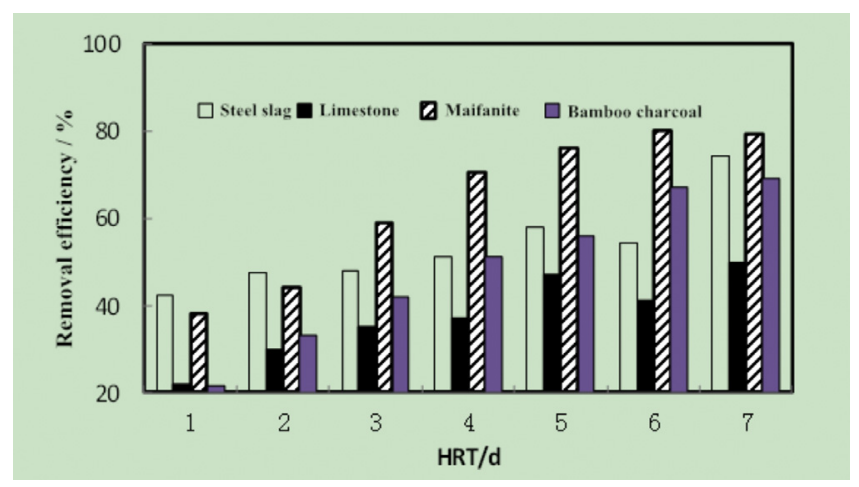

Fig. 5. Variations of TN removal efficiency with HRT.

\subsection{Effects of different substrates on $\mathrm{NH}_{3}-\mathrm{N}$ concentration}

Studies have found that there is a significant relationship between the efficiency of constructed wetland sewage treatment systems and the wetland substrates (Hua et al., 2013; Xu et al., 2015). The more the microbial biomass in wetland, the better is the pollutant removal. The number of nitrifying bacteria and denitrifying bacteria has a great impact on $\mathrm{NH}_{3}-\mathrm{N}$ removal efficiency; nitrification and denitrification are the major ways that wetland systems remove TP and $\mathrm{TN}$, while the microorganismliving environment provided together by aquatic plants and substrates determines the conditions favorable to the growth of microorganisms. However, $\mathrm{NH} 3-\mathrm{N}$ removal efficiency is also affected by other factors, causing the NH3-N removal efficiency of constructed wetland substrate systems to become unstable (Arunbabu et al., 2015).

As can be seen in Fig. 6, with the increase of HRT, the NH3-N removal efficiencies of all four substrates increase. When HRT is between 1 and 3 days, the removal efficiency is low. When HRT reaches 4 days, the removal efficiency increases greatly. When HRT is greater than 4 days, the ammonia removal efficiencies of steel slag and maifanite are about $80 \%$ and the removal efficiency of the bamboo charcoal system reaches about $75 \%$. Therefore, the NH3-N removal efficiencies of all three substrates systems are relatively better. When the system HRT is greater than 4 days, the NH3-N removal efficiencies of all four substrate systems become stable. When HRT reaches 6 days, the average $\mathrm{NH}_{3}-\mathrm{N}$ concentration indices in the final effluents are $2.9 \mathrm{mg} / \mathrm{L}, 6.3 \mathrm{mg} / \mathrm{L}, 3.6 \mathrm{mg} / \mathrm{L}$ and $4.7 \mathrm{mg} / \mathrm{L}$ respectively.

\section{Conclusions}

(1) The adsorption laws of COD, turbidity, TP and TN in rural household sewage with four types of medium fillers have been studied. The results show the models are better for the description of adsorption isotherms. The four types of medium wetland systems can effectively degrade COD, turbidity, TN, TP and NH3-N in rural household sewage. The effluent water quality meets the first class of A standard of the "Discharge standard of pollutants for municipal wastewater treatment plant" (GB18918-2002). The treatment efficiency of limestone wetland is slightly worse, but it can be speculated that it can also reach the standards if the effluent in the limestone system goes through a primary wetland treatment. This suggests that the applications of these four substrates in rural household sewage treatment is feasible, and the treatment efficiency of maifanite wetland system is the best. The theoretical maximum adsorption capacities of

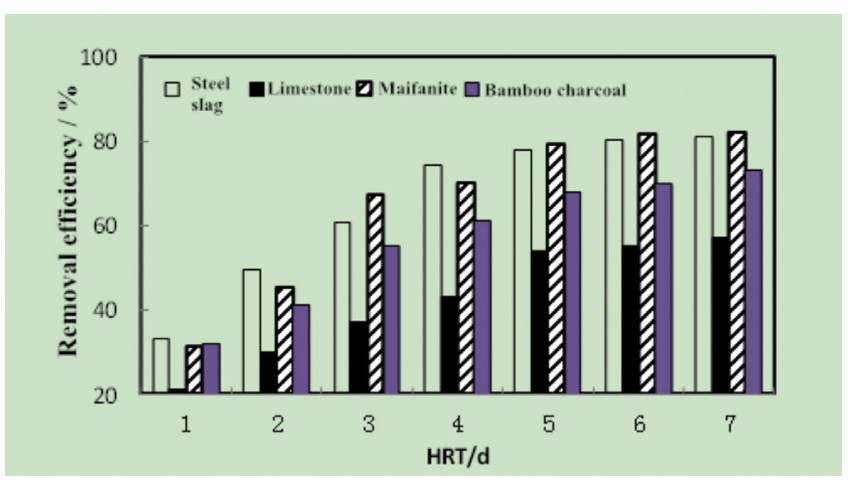

Fig. 6. Variations of $\mathrm{NH}_{3}-\mathrm{N}$ removal efficiency with HRT.

all media are ordered as maifanite $>$ steel slag $>$ bamboo charcoal > limestone.

(2) After integrating the pollutant removal efficiency of the filler's microstructure, components, static adsorption and dynamic adsorption, and considering the material production site and price factors, we suggest that engineers choose maifanite, steel slag and gravel as they have better overall performance and intermix them into a combined medium filler as a filler for on-site experimental systems.

(3) Since rural household sewage belongs to a kind of sewage whose composition is relatively fixed and the selected aquatic plants are more attractive, this approach can also be applied to tourist areas, resorts or scenic areas. The process is also very practical when it is used to deal with urban household sewage and wastewater, not only is its treatment efficiency better, but the treated water can be recycled to generate economic benefits, further reducing the cost of investment. The scientific and reasonable selection of fillers as a substrate, is the most important point in the construction and application of large area constructed wetland systems; it is also a subject in need of further study and exploration.

\section{Suggestions}

(1) Increase experimental studies into wetland systems under different load conditions; conduct scientific analysis to determine the optimum operating conditions of subsurfaceflow wetland systems, while optimizing the selection of fillers and ways of filling. In particular, we should consider the treatment process of wetland system terminals;

(2) Subsequent experiments can consider the use of the combined filler of natural zeolite + gravel + sandstone. This can not only effectively enhance the intensity of nitrification/ denitrification in wetland systems and improve the efficiency of denitrogenation in the wetlands, but can also further enhance wetland shock load capacity and antiblocking ability. The intensity of nitrification/denitrification can characterize the denitrogenation capacity and potential in wetland systems, and provides a reliable basis for the further optimization of wetlands substrate filler selection.

\section{Acknowledgment}

The paper is funded by The National Natural Science Foundation of China (Grant No.:51379219; Grant 71303203) and Zhejiang province Funds for Distinguished Young Scientists (Grant No.: LR15E090002). This research is also supported by the Environment 
and Conservation Fund by the Hong Kong Government (Project No: 9211073).

\section{References}

An, W., Zhou, X., Liu, X., Chai, P.W., Kuznicki, T., Kuznicki, S.M., 2014. Natural zeolite clinoptilolite-phosphate composite membranes for water desalination by pervaporation. J. Membr. Sci. 470, 431-438.

Arunbabu, V., Sruthy, S., Antony, Ignatius, Ramasamy, E.V., 2015. Sustainable greywater management with Axonopus compressus (broadleaf carpet grass) planted in sub surface flowconstructed wetlands. J. Water Process Eng. 7, 153-160.

Bajaj, Swati, Singh, Dileep K., 2015. Biodegradation of persistent organic pollutants in soil, water and pristine sites by cold-adapted microorganisms: mini review. Int. Biodeterior. Biodegrad. 100, 98-105.

Benmoussa, H., Tyagi, R.D., Campbell, P.G.C., 1997. Simultaneous sewage sludge digestion and metal leaching using an internal loop reactor. Water Res. 31, 2638-2654.

Boonsaner, Maliwan, Hawker, Darryl W., 2015. Transfer of oxytetracycline from swine manure to three different aquatic plants: implications for human exposure. Chemosphere 122, 176-182.

Chou, Wei-Lung, Wang, Chih-Ta, Chang, Shih-Yu, 2009. Study of COD and turbidity removal from real oxide-CMP wastewater by iron electrocoagulation and the evaluation of specific energy consumption. J. Hazard. Mater. 168, 1200-1207.

Cui, Lihua, Ouyang, Ying, 2015. Removal of nutrients from septic tank effluent with baffle subsurface-flow constructed wetlands. J. Environ. Manag. 153, 33-39.

Cui, Lihua, Ouyang, Ying, Gu, Wenjie, Yang, Weizhi, Xu, Qiaoling, 2013. Evaluation of nutrient removal efficiency and microbial enzyme activity in a baffled subsurface-flow constructed wetland system. Bioresour. Technol. 146, 656-662.

Dordio, A.V., Carvalho, A.J.P., 2013. Organic xenobiotics removal in constructed wetlands, with emphasis on the importance of the support matrix. J. Hazard. Mater. 15, 272-292.

Dordio, Ana V., Teimão, José, Ramalho, Idália, Palace Carvalho, A.J., Estêvão Candeias, A.J., 2007. Selection of a support matrix for the removal of some phenoxyacetic compounds in constructed wetlands systems. Sci. Total Environ. $380,237-246$

Feng, Chunhua, Huang, Liqiao, Yu, Hui, Yi, Xiaoyun, Wei, Chaohai, 2015. Simultaneous phenol removal, nitrification and denitrification using microbial fuel cell technology. Water Res. 76, 160-170.

Galanopoulos, Christos, Sazakli, Eleni, Leotsinidis, Michalis, Lyberatos, Gerasimos, 2013. A pilot-scale study for modeling a free water surface constructed wetlands wastewater treatment system. J. Environ. Chem. Eng. 1, 642-651.

Gao, Min, Simoneit, Bernd R.T., Gantar, Miroslav, Jaffé, Rudolf, 2007. Occurrence and distribution of novel botryococcene hydrocarbons in freshwater wetlands of the Florida Everglades. Chemosphere 70, 224-236.

Grossmann, Malte, 2012. Economic value of the nutrient retention function of restored floodplain wetlands in the Elbe River basin. Ecol. Econ. 83, 108-117.

Hattermann, F.F., Krysanova, V., Habeck, A., Bronstert, A., 2006. Integrating wetlands and riparian zones in river basin modelling. Ecol. Model. 199, 379-392.

Hua, G.F., Li, L., Zhao, Y.Q., Zhu, W., Shen, J.Q., 2013. An integrated model of substrate clogging in vertical flow constructed wetlands. J. Environ. Manag. 119, 67-75.

Hussain, Sabir, Aziz, Hamidi Abdul, 2011. Orthophosphate removal from domestic wastewater using limestone and granular activated carbon. Desalination 271, 265-272.

Lam, Lauho, Kurisu, Kiyo, Hanaki, Keisuke, 2015. Comparative environmental impacts of source-separation systems for domestic wastewater management in rural China. J. Clean. Prod. 104, 185-198.

Lu, Shibao, Pei, Liang, Bai, Xiao, 2015. Study on method of domestic wastewater treatment through new-type multi-layer artificial wetland. Int. J. Hydrogen Energy 40, 11207-11214.

Lu, S., Wang, J., Pei, L., 2016. Study on the effects of irrigation with reclaimed water on the content and distribution of heavy metals in soil. Int. J. Environ. Res. Public Health 13, 298.
Mackulak, Tomáš, Mosný, Michal, Škubák, Jaroslav, Grabic, Roman, Birošová, Lucia 2015. Fate of psychoactive compounds in wastewater treatment plant and the possibility of their degradation using aquatic plants. Environ. Toxicol. Pharmacol. 39, 969-973.

Matamoros, Víctor, Salvadó, Victòria, 2012. Evaluation of the seasonal performance of a water reclamation pond-constructed wetland system for removing emerging contaminants. Chemosphere 86, 111-117.

Mayo, A.W., Hanai, E.E., Kibazohi, O., 2014. Nitrification-denitrification in a coupled high rate - water hyacinth ponds. Physics Chem. Earth Parts A/B/C 72-75, 88-95.

Moreno, David, Pedrocchi, César, Comín, Francisco A., García, Mercedes, Cabezas, Alvaro, 2007. Creating wetlands for the improvement of water quality and landscape restoration in semi-arid zones degraded by intensive agricultural use. Ecol. Eng. 30, 103-111.

Oshima, Tatsuya, Kaneizumi, Keisuke, Ohe, Kaoru, Baba, Yoshinari, 2015. Synergistic effect of nitrogen-containing donors on extraction of divalent metal ions using p-tert-octylphenoxyacetic acid. Sep. Purif. Technol. 141, 301-306.

Pang, S.C., Masjuki, H.H., Kalam, M.A., Hazrat, M.A., 2013. Liquid absorption and solid adsorption system for household, industrial and automobile applications: a review. Renew. Sustain. Energy Rev, 28, 836-847.

Samsó, Roger, García, Joan, 2013. Bacteria distribution and dynamics in constructed wetlands based on modelling results. Sci. Total Environ. 461-462, 430-440.

Saumya, S., Akansha, S., Rinaldo, J., Jayasri, M.A., Suthindhiran, K., 2015. Construction and evaluation of prototype subsurface flow wetland planted with Heliconia Angusta for the treatment of synthetic greywater. J. Clean. Prod. 91 235-240.

Shao, Ling, Wu, Zi, Zeng, L., Chen, Z.M., Zhou, Y., Chen, G.Q., 2013. Embodied energy assessment for ecological wastewater treatment by a constructed wetland. Ecol. Model. 252, 63-71.

Smol, Marzena, Kulczycka, Joanna, Henclik, Anna, Gorazda, Katarzyna, Wzorek, Zbigniew, 2015. The possible use of sewage sludge ash (SSA) in the construction industry as a way towards a circular economy. J. Clean. Prod. 95, 45-54.

Tachikawa, Mariko, Yamanaka, Kenzo, 2014. Synergistic disinfection and removal of biofilms by a sequential two-step treatment with ozone followed by hydrogen peroxide. Water Res. 64, 94-101.

Verlicchi, Paola, Zambello, Elena, 2014. How efficient are constructed wetlands in removing pharmaceuticals from untreated and treated urban wastewaters? A review. Sci. Total Environ. 470-471, 1281-1306.

Vohla, Christina, Kõiv, Margit, John Bavor, H., Florent Chazarenc, Ülo Mander, 2011. Filter materials for phosphorus removal from wastewater in treatment wetlands-a review. Ecol. Eng. 37, 70-89.

Vymazal, Jan, Švehla, Jaroslav, Kröpfelová, Lenka, Chrastný, Vladislav, 2007. Trace metals in Phragmites australis and Phalaris arundinacea growing in constructed and natural wetlands. Sci. Total Environ. 380, 154-162.

Wu, Haiming, Zhang, Jian, 2015. A review on the sustainability of constructed wetlands for wastewater treatment: design and operation. Bioresour. Technol. 175, 594-601.

Xu, Defu, Wang, Lin, Li, Huili, 2015. The forms and bioavailability of phosphorus in integrated vertical flow constructed wetland with earthworms and different substrates. Chemosphere 134, 492-498.

Yang, Wei, Song, Junnian, Higano, Yoshiro, Tang, Jie, 2015. Exploration and assessment of optimal policy combination for total water pollution control with a dynamic simulation model. J. Clean. Prod. 102, 342-352.

Zhang, Dongqing, Gersberg, Richard M., Keat, Tan Soon, 2009. Constructed wetlands in China. Ecol. Eng. 35, 1367-1378.

Zhang, Y.M., Huang, G., Lu, H.W., He, Li, 2015. Planning of water resources management and pollution control for Heshui River watershed, China: a full credibility-constrained programming approach. Sci. Total Environ. 524-525. 280-289.

Zhi, Wei, Ji, Guodong, 2012. Constructed wetlands, 1991-2011: a review of research development, current trends, and future directions. Sci. Total Environ. 441, $19-27$. 